\title{
Coulisses
}

Revue de théâtre

2 | Automne 1990

Spécial Festival des idées : Besançon ville ouverte aux jeunes

\section{Les mots dits}

Hyleg, Christophe Delacroix, Gérard Marie-Forestier et Rédaction

\section{(2) OpenEdition \\ Journals}

Édition électronique

URL : http://journals.openedition.org/coulisses/1587

DOI : 10.4000/coulisses. 1587

ISSN : 2546-9460

Éditeur

Presses universitaires de Franche-Comté

Édition imprimée

Date de publication : 1 novembre 1990

Pagination : $\mathrm{np}$

ISSN : 1150-594X

\section{Référence électronique}

Hyleg, Christophe Delacroix, Gérard Marie-Forestier et Rédaction, «Les mots dits », Coulisses [En ligne], 2 | Automne 1990, mis en ligne le 04 juillet 2017, consulté le 23 octobre 2019. URL : http:// journals.openedition.org/coulisses/1587; DOI : 10.4000/coulisses.1587

Ce document a été généré automatiquement le 23 octobre 2019.

Coulisses 


\section{Les mots dits}

\section{Hyleg, Christophe Delacroix, Gérard Marie-Forestier et Rédaction}

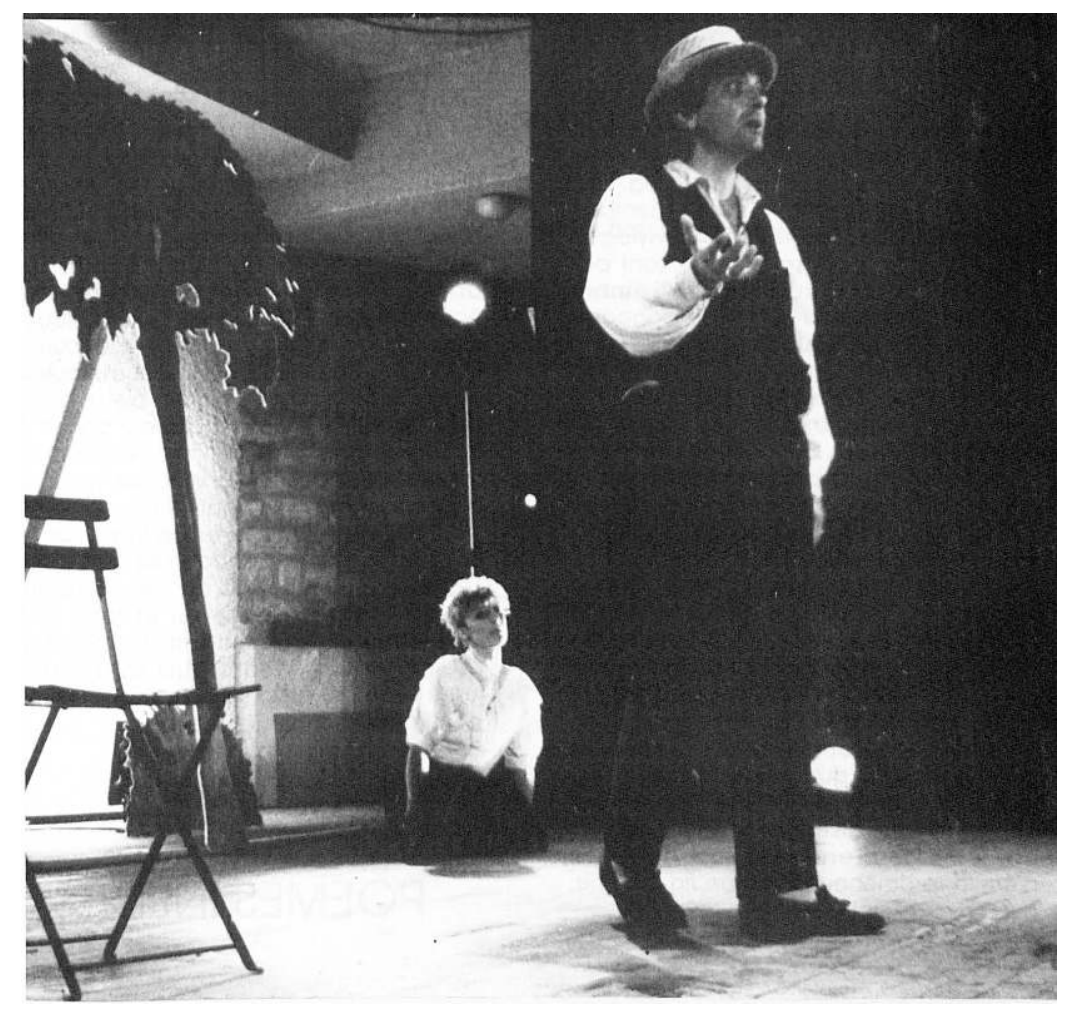

(c) Collectif Photo BVOJ 90.

1 Petit-Kursaal, 21 heures. Une quarantaine de spectateurs dans la salle; on est samedi et la poésie n'est pas un «créneau porteur » comme on dit aujourd'hui. Sur la scène, un banc vert et un lampadaire. Chant d'encre présente son premier spectacle public.

2 Les textes sont des poèmes d'auteurs consacrés: Queneau, Verlaine, Aragon et de poètes (encore) inconnus: Hyleg, GM. Forestier, C. Delacroix, tous trois membres de l'association Chant d'encre. Hyleg et GM. Forestier, précisons-le, ne sont pas totalement des auteurs de l'ombre puisqu'ils ont été lauréats du concours national «Le club des 
poètes » en 1989 et à ce titre ont eu des poèmes publiés dans la revue du club. Deux thèmes structurent le spectacle : l'écriture et l'amour. Comme la poésie se lit (aussi), le lecteur trouvera trois poèmes inédits extraits des Mots Dits dans les pages qui suivent. L'objectif de Chant d'encre est de faire que la poésie soit plus largement accessible, non réservée à un petit cercle de connaisseurs. "Notre but est de donner une image différente de la poésie. On a envie que ce soit autre chose qu'une suite de textes et ce qu'on souhaite, c'est faire partager quelque chose qui peut être très beau, vivant. » Le propos n'est donc pas de réciter un poème face au public mais de mettre la poésie en spectacle. Chaque texte est mis en scène; le diseur est personnage : poète sombre en proie à la difficulté d'écrire, promeneuse version fin $\mathrm{XIX}^{\mathrm{e}}$, avec ombrelle et canotier.

Entre les deux parties en direct s'intercale un diaporama, combinaison d'images, de poèmes dits et de musique. Les diapositives non figuratives, création de C. Delacroix, séduisent le regard... mais le texte poétique est étouffé par une musique dominatrice. La poésie sollicite une écoute particulière car elle est musique, d'où la difficulté de lui associer une source musicale externe avec laquelle, elle puisse entrer en résonance. On peut aussi regretter l'utilisation du micro qui donne à la poésie des sonorités «métalliques » et trouble l'écoute. Seule la voix nue, avec sa musicalité propre, peut dire le poème " hésitation prolongée entre le son et le sens " selon la très belle formule de Valéry. Les acteurs, conscients de ce problème, envisagent un travail sur la voix afin d'éliminer la sonorisation. Un point à souligner : les spectateurs sont restés jusqu'au terme de la soirée, preuve que la poésie peut trouver un public.

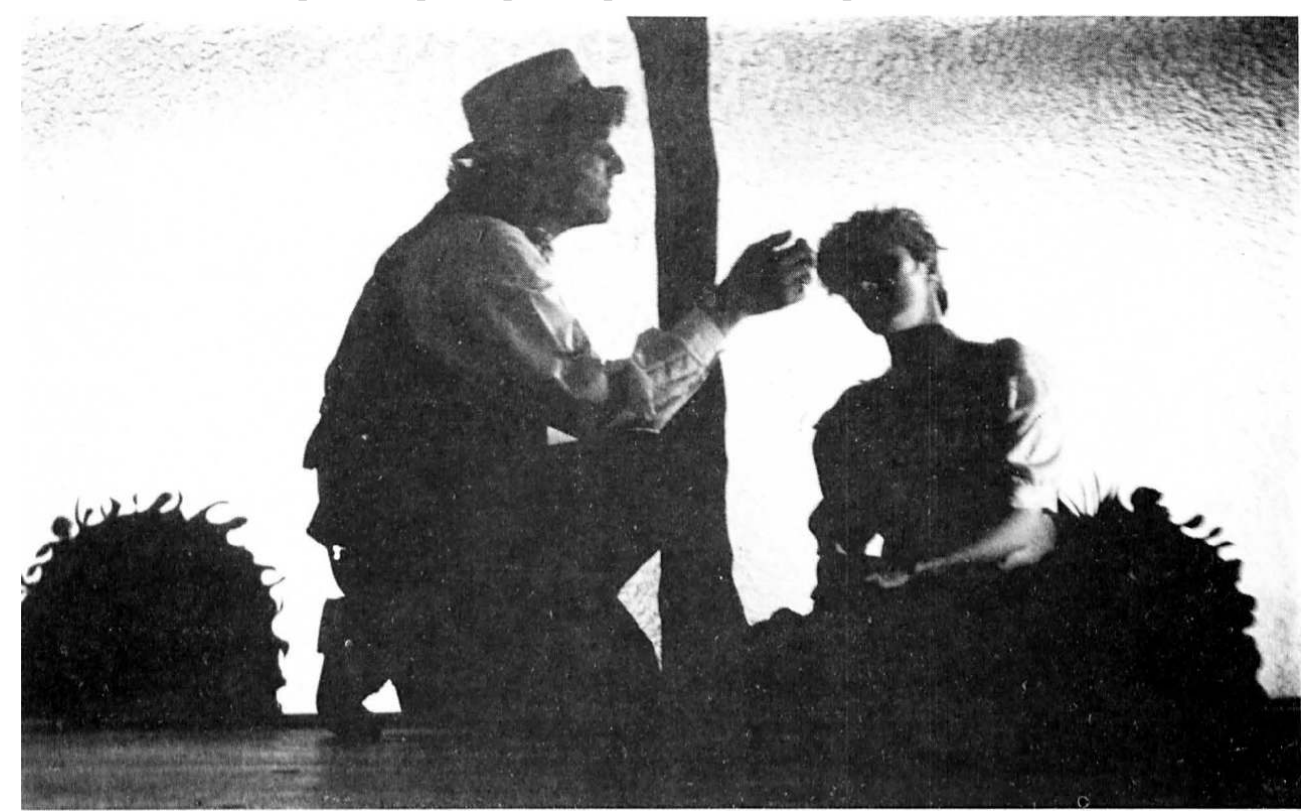

(c) Collectif Photo BVOJ 90.

\section{Poèmes inédits}

\section{Lits...}

L'érotisme latent de ta peau qui frissonne Appelle de ses vœux le baiser voyageur Épiderme frileux d'une froidure polissonne Nouvel élan du corps qui troque ses couleurs 
Vérité de nos sens, horloges de nos orgasmes Ces milliers de volcans font lever mon stylo J'écris ces quelques mots dans ta chatte papier L'encre de mon désir ne fait que quelques taches La main qui te caresse en oublie le poète L'alphabet de nos sens s'écrit au bas d'une feuille Fera naître sous les draps la rime de l'émotion Captivante création de phrases qui se suivent Écriture sensuelle qui rapproche les arts L'expression reste humaine lorsqu'elle couve le désir Les élans se mélangent sur le blanc du papier Les pages de nos ardeurs remplissent le cahier Éros est son complice, il en tourne les feuilles Un jour de ton plaisir je ferai une chanson.

Hyleg

\section{Mandragore}

C'en était trop pour les nerfs d'une seule aventure Trop solide pour y abandonner des illusions Trop feu pour éveiller une quelconque amertume : L'élixir de sang virginal et de sueur Dissout dans l'infâme alcool du temps S'est peu à peu figé sur les lèvres, Il a scellé la promesse des premiers baisers Aux ivresses d'une escale dans un port plus méritoire. Les voix sont de cire ou de chair inerte Inertie des spasmes suicidaires de chaque objet Quand le silence des êtres s'appesantit, État d'âme morte quand il s'éternise au futur impossible. Racines aux formes humaines Jaillissant d'un antre inconnu Pour une absence à laquelle on s'est résigné. Racines ensemencées par les pendus d'après l'amour Copiant leur potence sur les perdus avant la mort.

Christophe Delacroix

\section{Chant d'encre}

Lavande bleue, lavande noire, Fleur d'encre dans mon encrier, Dans la nuit, où sombre l'ivoire J'écris, j'écris à en crier.

J'écris sur du papier de chine, C'est une nuit à rossignol On entend grincer la machine, L'automate, le grand guignol. Dans une épaisse cécité Je trempe ma plume d'ivoire J'écris sans électricité C'est une encre divinatoire. Champ profond où la vigilance Se dresse comme un grand cyprès, Fond du vent où vibrent des lances Éclatantes, sourdes, si près... On entend passer des sanglots 
Comme de grandes roues sonores Chagrin centrifuge en solo Qui dans la nuit sème son or... Lavande bleue, lavande noire, Neige d'encre qui s'exfolia Sur le papier où vient pleuvoir L'ombre blanche des magnolias. Près de la source du lavoir La musique de l'eau me grise, Je l'entends mais ne puis la voir Ma tête tourne dans la bise. Je me détache de ma forme Et dans l'eau blanche je me lave. Le monde vrai n'a pas de norme L'encre s'enflamme et se fait lave. Lavande bleue, lavande noire, Je m'éveille quand tout s'endort Je fends la nuit de mes nageoires, Je traverse en toussant de l'or. Le courant de ce fleuve d'ombre Aux vertiges arborescents Où ma plume d'ivoire sombre Dans l'encre adorée de mon sang. Gérard Marie-Forestier 